\title{
Análisis jurídico del funcionamiento del Comité Ejecutivo del Sistema de Integración Centroamericana
}

\author{
Eymi Lissette Esquivel Avendaño* \\ Universidad Centroamericanam Nicaragua \\ esquivel_amy@hotmail.com
}

Fecha de recibido: 8 de noviembre de 2015 Fecha de aprobación: 14 de diciembre de 2015

\section{Resumen}

El presente artículo científico toma como punto central el análisis del funcionamiento actual del Comité Ejecutivo del Sistema de Integración Centroamericana, órgano permanente creado por el Protocolo de Tegucigalpa y conformado por representantes de cada uno de los Estados que conforman el SICA. Este artículo analiza el poder de decisión en el SICA y la producción normativa del Comité Ejecutivo contrastándola con las atribuciones conferidas. Se estudia la perspectiva histórica desde su nacimiento, sus atribuciones, la forma de manifestación de consentimiento, su conformación y la normativa que regula su funcionamiento, A partir de todo lo anterior, se realizan propuestas concretas para una renovación institucional.

\section{Palabras claves}

\section{Comité Ejecutivo, SICA, Integración Centroamericana, Institucionalidad regional centroamericana}

\section{Abstract}

The present scientific article takes as a central point the analysis of the current operation of the Executive Committee of the Central America Integration System, a permanent body created by the Protocol of Tegucigalpa and consisting of representatives from each of the States that composes the SICA. This article analyzes the decision making power at SICA and the normative production of the Executive Committee contrasting it with the powers conferred. The historical perspective is studied since its birth, its powers, the manifestation of consent form, their composition and the normative of operation. From all above, are made concrete proposal for institutional renewal.

\section{Keywords:}

Executive Committee, SICA, Central American Integration, Central American Regional Institutions

* Este artículo de investigación fue realizado en el marco de la Maestría Regional en Integración Centroamericana y Desarrollo ejecutada por la Universidad Rafael Landívar de Guatemala, Universidad "José Simeón Cañas" de El Salvador y la Universidad Centroamericana de Nicaragua con apoyo del fondo España-SICA. 
Introducción. I. Perspectiva histórica del Comité Ejecutivo del SICA. 2. Producción normativa en el SICA, especial referencia al Comité Ejecutivo. 2.I. Regulación del Protocolo de Tegucigalpa. 2.2 Reglamento de los actos normativos del I de diciembre de 2005. 2.3 Actual Reglamento para la adopción de decisiones del 24 de junio del año 2013. 2.4. Elementos diferenciadores entre ambos instrumentos. 2.5. Actos normativos producidos por el Comité Ejecutivo. 3. Comité Ejecutivo del SICA: su funcionamiento. 3.I Regulación normativa. 3.2. Conformación del órgano. 3.3. Periodicidad de sus reuniones establecida por los instrumentos jurídicos. 3.4. Atribuciones del Comité Ejecutivo. 3.5 Reglamentación del Comité Ejecutivo del SICA. 3.5.I El reglamento del Comité Ejecutivo del SICA Diciembre de 2007. 3.5.2. Reglamento de Organización y Funcionamiento del Comité Ejecutivo Marzo de 20/2. 4. El papel de la Secretaría General del SICA y su vinculación con el Comité Ejecutivo 5. Funcionamiento de Grupos ad hoc. Conclusiones. Lista de referencias bibliográficas

\section{Introducción}

La integración centroamericana es, en nuestros días, una de las más prometedoras acciones regionales para el desarrollo de nuestros pueblos. El crecimiento y progreso de la integración centroamericana ha tenido importantes repercusiones en diversos ámbitos como lo político, social, cultural, ambiental y económico que han permitido el desarrollo sostenido de la región.

La institucionalidad del sistema de integración centroamericana es bastante compleja, se trata de un conjunto de órganos, instituciones y secretarías que han crecido y se han especializado en el transcurso del tiempo.

Este artículo forma parte de un más amplio trabajo de investigación que aborda la perspectiva jurídica y política del Comité Ejecutivo del SICA realizado para la Maestría Regional en Integración Centroamericana ejecutada por las Universidades Jesuitas de Centroamérica. Para su realización fue necesaria la entrevista a actores políticos y académicos relacionados con el Comité Ejecutivo, los resultados de estas entrevistas son abordados a lo largo del artículo.

Este artículo científico aborda el Comité Ejecutivo del SICA como uno de los órganos permanentes del Sistema desde una perspectiva jurídica analizando su creación normativa a través del Protocolo de Tegucigalpa a la Carta de la ODECA de 199I, la producción normativa del Sistema, con especial referencia al Comité Ejecutivo y el funcionamiento de este órgano.

El funcionamiento del Comité Ejecutivo es abordado a través de la regulación jurídica de este, su conformación, la periodicidad de sus reuniones, sus atribuciones conferidas por el derecho comunitario centroamericano, su reglamentación, los grupos ad hoc que trabajan cercanos a este órgano y su relación con la Secretaría General del SICA.

Como resultado de la investigación realizada se presentan a lo largo de este artículo propuestas de transformaciones que conduzcan a una renovación del Comité Ejecutivo del SICA en la búsqueda de potenciar el alcance de sus acciones en el ámbito regional. 


\section{Perspectiva histórica del Comité Ejecutivo del SICA}

El Comité Ejecutivo del Sistema de integración Centroamericana es creado por el Protocolo de Tegucigalpa a la Carta de la ODECA en 199I, la presente investigación recorre históricamente su creación hasta nuestros días. A pesar de haber sido creado por este instrumento en 199I, se reconoce en esencia una aproximación al mismo, en la Segunda Carta de la ODECA del 12 de diciembre de 1962, que crea el Consejo Ejecutivo de la ODECA.

La Carta de la ODECA del 14 de octubre de $195 \mathrm{I}$ que crea la Organización de Estados Centroamericanos no planteaba entre sus órganos, uno de la naturaleza del Comité Ejecutivo, no es sino hasta en 1962 que se habla de un órgano con características similares al Comité Ejecutivo de hoy en día.

Esta Carta de la ODECA de 1962 contempla órganos a los previstos en la primer Carta de la ODECA de 195I, reconoce como órganos el Consejo Ejecutivo, el Consejo Legislativo, la Corte de Justicia Centroamericana, el Consejo Cultural y Educativo, y el Consejo de Defensa Centroamericano.

Ese Consejo Ejecutivo creado por la Carta de la ODECA de 1962 se trata de un órgano con configuración permanente con sede en la ciudad de San Salvador (Artículo 3), lo que no era usual dentro de la Organización, puesto que sus principales órganos no tenían carácter de permanente.

A pesar de la existencia de la Conferencia de Ministros de Relaciones Exteriores como órgano principal (Artículo 3), la Carta de la ODECA planteaba que el Consejo Ejecutivo estaría conformado por los Ministros de Relaciones Exteriores o sus representantes (Artículo 7). A este nuevo órgano se le otorga la representación legal de la organización, función actualmente desempeñada por la Secretaría General del SICA creada por el Protocolo de Tegucigalpa de 1991.

Este Consejo debía reunirse una vez por semana (Artículo 8), su principal función otorgada era de dirigir y coordinar la política de la organización para lograr el cumplimiento de sus fines, para su funcionamiento, el Consejo Ejecutivo debía designar a un Secretario y el personal necesario para la realización de las funciones administrativas (Artículo 9). Así mismo, el Consejo Ejecutivo sería el medio de comunicación entre la organización y sus miembros.

La regulación de este Consejo Ejecutivo es para nosotros el nacimiento, al menos normativamente, del órgano que en 199I a través del Protocolo de Tegucigalpa a la Carta de la ODECA pasó a denominarse Comité Ejecutivo del SICA, órgano central de este artículo.

De lo anterior es relevante señalar la necesidad de un órgano con conformación política pero facultades ejecutivas que permitiera hacer caminar la Organización de Estados Centroamericanos para el logro de sus fines, es desde este momento palpable, la preocupación por crear un órgano colegiado en el que se representaran los intereses de cada Estado en el proceso de integración regional, órgano creado con visión permanente y el único órgano que se planteaba se reuniese con frecuencia semanal.

Esto evidencia, como bien señala Argüello (2014) que el diseño institucional del hoy Comité Ejecutivo data de aproximadamente $5 \mathrm{I}$ años atrás, en contraste con sus 6 años de conformación y funcionamiento actual.

El Protocolo de Tegucigalpa a la Carta de la ODECA del 13 diciembre de 199I, es hoy la norma jurídica fundamental de la integración centroamericana, su promulgación por parte de los Presidentes Centroamericanos responde a la necesidad de actualizar, casi 30 años después, el marco jurídico de la Organización de Estados Centroamericanos en respuesta a las necesidades que enfrentaba la región.

En palabras de Chorro (2010):

El nuevo sistema de integración se imbricó en prácticas, costumbres, mecanismos, normativas y problemas estructurales del antiguo proceso integracionista que no desembocó en un verdadero cambio institucional. Esa herencia que le transfieren al SICA le impide asumir con solvencia los nuevos retos y le aminora la velocidad de adaptación al nuevo entorno (p.27). 
En este nuevo instrumento jurídico se establecen los propósitos y principios del Sistema de Integración Centroamericana, se modifica la estructura organizacional de la ODECA, órganos llamados a contribuir de forma primordial a lo preceptuado el Protocolo de Tegucigalpa. El Protocolo de Tegucigalpa regula en su artículo 12 que son órganos del sistema: la Reunión de Presidentes, el Consejo de Ministros, el Comité Ejecutivo y la Secretaría General. El Protocolo de Tegucigalpa también contempla otros órganos e instituciones que conforman el SICA.

La Reunión de Presidentes continúa siendo el órgano supremo del SICA (Artículo I3), el Consejo de Ministros de Relación Exteriores es ahora el órgano principal de coordinación (Artículo 16), por su parte el Comité Ejecutivo y la Secretaría General son los órganos permanentes (Artículo 23).

A pesar de haber sido creado en 199I a través del Protocolo de Tegucigalpa, el Comité Ejecutivo no entro en funciones sino hasta el año 2008 , las personas entrevistadas en esta investigación han coincidido en que ha sido la voluntad política la que ha determinado históricamente la conformación de este órgano más allá de lo preceptuado en los instrumentos jurídicos de derecho comunitario, lo que por supuesto erosiona el sistema jurídico de la integración centroamericana.

Otras de las razones señaladas para determinar el porqué del retraso en la conformación del órgano han sido las limitaciones para nombrar a alguien a partir de la debilidad institucional de los gobiernos, la ausencia de estructuras internas en temas de integración y la ausencia de un reglamento que regulara sus funciones, su configuración jurídica comunitaria versus el intergubernamentalismo promovido por los Estados.

Para el ex Secretario General del SICA Juan Daniel Alemán, al responder a nuestra entrevista, 5 cuestiones incidieron y han marcado la puesta en marcha y el funcionamiento del Comité Ejecutivo. Primero la falta de claridad sobre el modelo de integración que se quería y la carencia de liderazgos, la falta de entendimiento de las dimensiones para el fortalecimiento de la integración de un órgano de carácter permanente que actúe junto con la Secretaría General, la no diferenciación entre un organismo intergubernamental y la naturaleza propia del SICA, el desinterés de secretarios generales y el poco agregado que le brindarían los delegados de los países que no tendrían el funcionamiento del órgano como prioridad y finalmente, la idoneidad de algunos representantes ante el órgano que no realizan la dicotomía entre la dimensión nacional y regional.

\section{Producción normativa en el SICA, especial referencia al Comité Ejecutivo}

El poder de decisión posee distintas formas de manifestación en el derecho comunitario, en el Sistema de integración Centroamericana las decisiones se manifiestan a través de actos normativos producidos concretamente por aquellos órganos facultados para ello. A continuación, abordamos los principales instrumento de derecho comunitario que definen este tema.

\section{I Regulación del Protocolo de Tegucigalpa}

El Protocolo de Tegucigalpa hace mención de algunas modalidades o tipos de actos normativos que pueden producir los principales órganos del Sistema de Integración Centroamericana, así por ejemplo, el artículo 4 establece las declaraciones de la Reunión de Presidentes; el artículo 10 hace mención de la publicidad de las resoluciones de los órganos e instituciones del SICA; el artículo 12 se refiere a resoluciones; el artículo 24 hace referencia a la aprobación de reglamentos por parte del Comité Ejecutivo del SICA, la aprobación de su reglamento administrativo por parte de la Secretaría General (artículo 26); acuerdos al referirse al establecimiento de la Sede del Sistema de Integración Centroamericana (artículo 29); y recomendaciones (artículo 17, 2 y 31 ).

Lo anterior representa una confusión en cuanto a los tipos de actos normativos que cada órgano puede producir, no se establece en qué tipo de instrumento los Consejos de Ministros tomarán sus decisiones y tampoco se hace referencia a qué diferencia una declaración, de una resolución, un reglamento y una recomendación, esto representa una dificultad de aplicación del Protocolo de Tegucigalpa y genera, como consecuencia, inseguridad 
jurídica en el derecho comunitario, incumpliendo así el artículo 4 literal g) que establece la seguridad jurídica como principio fundamental de la integración centroamericana.

Las carencias señaladas en este sentido, se han intentado poco a poco suplir con instrumentos jurídicos derivados de derecho comunitario, por primera vez a través del reglamento de los actos normativos del Sistema de Integración Centroamericana aprobado por el Consejo de Ministros de Relaciones Exteriores en el año 2005 y finalmente, a través del reglamento para la adopción de decisiones del SICA aprobado por el Comité Ejecutivo en el año 2013 derogatorio del anterior, aunque como veremos a continuación aún quedan vacíos normativos que suplir.

\subsection{Reglamento de los actos normativos del I de diciembre de 2005}

El artículo 2 de las disposiciones transitorias del Protocolo de Tegucigalpa establece que mientras se integre el Comité Ejecutivo del SICA sus atribuciones serán asumidas directamente por el Consejo de Ministros de Relaciones Exteriores. Esta disposición hoy carece de validez por la existencia del Comité Ejecutivo, no obstante, fue plenamente válida desde 199/ hasta inicios del año 2008 fecha en que se reunió por primera vez el Comité Ejecutivo del SICA.

Es importante señalar que para el año 1993, se tiene referencia a la existencia de un proyecto de reglamento de actos institucionales del Sistema de la Integración Centroamericana presentado por la Secretaría General del SICA, que debía ser sometido a su aprobación ante el Consejo de Ministros de Relaciones Exteriores de acuerdo a lo establecido en la Agenda de Guatemala de la XIV Reunión Ordinaria de Presidentes Guatemala del 29 de octubre de 1993, al parecer este documento nunca fue aprobado.

El Reglamento de los actos normativos del año 2005 regulaba los actos normativos emanados de la Reunión de Presidentes y el Consejo de Ministros (Artículo I), este instrumento define por primera vez el significado de acto normativo como "acto voluntario que crea, regula, ordena, modifica o extingue relaciones de derecho" (Artículo 2).

Es importante mencionar las discusiones doctrinales sobre la naturaleza de regular en un instrumento jurídico de derecho comunitario derivado un tema tan fundamental para el funcionamiento de la institucionalidad Centroamericana sobre todo porque el órgano del que provino este instrumento es jerárquicamente inferior a otros órganos fundamentales a los que se les regula su producción normativa, (García Palacios, Budier, Miranda, Gazo Peña y Blandino López, 2010), de forma general compartimos esta postura aun cuando valoramos positivamente el esfuerzo de algunos órganos por ordenar las actuaciones de la institucionalidad regional que se ha destacado por su dispersión.

De acuerdo a este instrumento, la Reunión de Presidentes podía producir cuatro tipos de actos normativos en el ejercicio de sus funciones: declaraciones, acuerdos, decisiones y resoluciones (Artículo 4), excediendo con ello lo preceptuado en el Protocolo de Tegucigalpa que solamente enunciaba las Declaraciones como acto normativo de la Reunión de Presidentes, sobre la posibilidad de presentar iniciativas a la Reunión de Presidentes, este instrumento no hacer referencia aunque como señalan García Palacios, Budier y et. Al (20l0), el Protocolo de Tegucigalpa en apariencia habilita al Consejo de Ministros de Relaciones Exteriores para ello, así como el Protocolo de reformas al Tratado Constitutivo del Parlamento Centroamericano y otras instancias habilitan al PARLACEN para proponer iniciativas en materia de integración regional.

Por su parte, el Consejo de Ministros podía aprobar cuatro tipos de actos normativos: resoluciones, reglamentos, acuerdos y recomendaciones, en cuanto al Consejo de Ministros de Relaciones Exteriores establece que podrá emitir decisiones en el ejercicio de su función principal de coordinación del sistema (Artículo I3). 
En relación al Comité Ejecutivo este instrumento solamente establecía que deberá aprobar los reglamentos e instrumentos elaborados por las Secretarías u otros órganos del Sistema de Integración Centroamericana (Artículo 16), copiando de forma literal lo preceptuado en el artículo 24 inciso f) del Protocolo de Tegucigalpa.

Las atribuciones otorgadas al Comité Ejecutivo hacían necesaria la producción de otro tipo de actos normativos para dar cumplimiento a sus competencias, consideramos que lo anterior justificó que entre febrero del 2008 y el 26 de junio de 2013, el Comité Ejecutivo promulgara diez resoluciones, a pesar de que normativamente no se contemplaba como un órgano con capacidad para promulgar este tipo de actos normativos o al menos este reglamento de actos normativos no preveía esta posibilidad.

Una carencia señalada a este instrumento, que al parecer no se suple en el vigente reglamento para la adopción de decisiones del 2013, es la falta de regulación sobre el procedimiento para la adopción de un acto normativo (García Palacios, Budier y et. Al., 20l0), es decir, cual es el procedimiento que debe seguirse para tener como resultado la producción de un acto normativo.

La falta de regulación procedimental al respecto de la creación de actos normativos y sus efectos jurídicos no contribuye a la transparencia y seguridad jurídica del funcionamiento de la institucionalidad regional, ya García Palacios, Budier y et. Al (20l0) plantaban la necesidad de reformar este instrumento para superar sus vacíos jurídicos.

\subsection{Actual Reglamento para la adopción de decisiones del 24 de junio del año 2013}

El 24 de junio del año 2013, el Comité Ejecutivo aprueba el Reglamento para la adopción de decisiones del SICA que deroga el previamente citado reglamento de actos normativos. Este instrumento jurídico regula las decisiones emanadas de tres de los órganos del sistema recogidos en el artículo 12 del Protocolo de Tegucigalpa: La Reunión de Presidentes, el Consejo de Ministros y el Comité Ejecutivo.

El Reglamento para la adopción de decisiones del SICA establece que la Reunión de Presidentes toma sus decisiones a través de mandatos contenidos en una declaración (artículo 3), para lo cual se define el término declaración como un acto político que expresa la voluntad de la Reunión de Presidentes para garantizar la armonización y coordinación del SICA, los mandatos que se encuentran contenidos en las declaraciones son decisiones que tienen la finalidad de establecer directrices a los órganos, secretarías e instituciones (Artículos 4 y 5).

Por su parte, el Consejo de Ministros puede producir resoluciones, reglamentos, acuerdos y recomendaciones; la definición de cada uno de estos no sufrió alteración alguna respecto al derogado reglamento de actos normativos (Artículos al 7 al 12).

Este reglamento contempla que el Comité Ejecutivo del SICA tomará sus decisiones por medio de resoluciones y recomendaciones, indicando que las resoluciones tendrán carácter vinculante, lo que podría entenderse como que estos serán de obligatorio cumplimiento para sus destinatarios (Artículo I3), no hace referencia al concepto de resoluciones o recomendaciones específicamente para este órgano por lo que podríamos interpretar que se trata del mismo concepto preceptuado para el Consejo de Ministros.

El reglamento para la adopción de decisiones contempla un capítulo para la integración de los órganos del SICA en el que se regula quienes están facultados para integrar la Reunión de Presidentes, el Consejo de Ministros y el Comité Ejecutivo del SICA, se establece adicionalmente la responsabilidad de la Secretaría General de mantener la información relacionada a los titulares de cada órgano debidamente actualizada.

Es dable destacar que a pesar de ser este reglamento para la adopción de decisiones en el SICA un importante esfuerzo institucional por mejorar el ordenamiento jurídico comunitario y propiciar la seguridad jurídica en el ejercicio de las funciones de los principales órganos del Sistema, se trata de una norma de derecho derivado y 
algunas de sus regulaciones por su trascendencia y valor jurídico deben estar reguladas en una norma originaria de derecho comunitario.

El Reglamento para la adopción de decisiones en el SICA ha venido a llenar o suplir vacíos jurídicos no regulados en el Protocolo de Tegucigalpa, sin embargo, a nuestro criterio esta no es una solución óptima teniendo en cuenta que la regulación sobre la adopción de decisiones en el sistema es un tema fundamental que debió haber sido regulado por el órgano supremo, la Reunión de Presidentes. Es contradictorio que un órgano como el Comité Ejecutivo del SICA regule los tipos de actos normativos que debe emitir un órgano jerárquicamente superior.

\subsection{Elementos diferenciadores entre ambos instrumentos}

Entre el Reglamento de los actos normativos del SICA del año 2005 y el Reglamento para la adopción de decisiones del año 2013 existen importantes elementos diferenciadores que vale la pena destacar:

- Aparece el Comité Ejecutivo como ámbito de aplicación del reglamento

Mientras en el derogado reglamento de actos normativos, el ámbito de aplicación se centraba en las decisiones de la Reunión de Presidentes y el Consejo de Ministros, el reglamento para la adopción de decisiones contempla como ámbito de aplicación también las decisiones que surjan del Comité Ejecutivo reconociéndose de esta forma la potestad de decisión de este órgano en el sistema de integración centroamericana.

- Se regula por primera vez el contenido de las decisiones y las actas de la Reunión de Presidentes, el Consejo de Ministros y el Comité Ejecutivo.

Hasta la promulgación de este reglamento, no existía seguridad jurídica ni homogeneidad en el contenido de las decisiones como instrumentos jurídicos que conforman el ordenamiento jurídico comunitario, se valora positivamente esta regulación porque permite uniformar el contenido de las actas y decisiones, brindando orden y seguridad jurídica al sistema.

- Se introduce el concepto de decisiones

El reglamento para la adopción de decisiones del SICA por primera vez define que se debe entender por decisión estableciendo que se trata de una "expresión de voluntad de los órganos del SICA establecidos en el artículo 12 letras a), b) y c), del Protocolo de Tegucigalpa en el ejercicio de sus competencias manifestada por medio de mandatos, resoluciones, reglamentos, acuerdos y recomendaciones" (Artículo 2).

- Introduce el concepto de consenso

Si bien el Protocolo de Tegucigalpa se pronuncia sobre la forma de tomar las decisiones en la Reunión de Presidentes y el Consejo de Ministros, es hasta en este instrumento jurídico que se introduce el concepto de consenso.

- La Reunión de Presidentes pasa de producir cuatro tipos de actos normativos a uno.

El Reglamento de actos normativos derogado excedía lo preceptuado en el Protocolo de Tegucigalpa al establecer que la Reunión de Presidentes además de Declaraciones podía emitir acuerdos, decisiones y resoluciones (Artículo 4), este exceso ha sido superado por el nuevo reglamento para la adopción de decisiones que establece que la Reunión de Presidentes solamente puede emitir declaraciones. 
- Establecimiento de la responsabilidad del Comité Ejecutivo de crear un procedimiento para adopción de mandatos de la Reunión de Presidentes

El reglamento para la adopción de decisiones del SICA contempla la responsabilidad del Comité Ejecutivo del SICA de establecer un procedimiento para la adopción de los mandatos de la Reunión de Presidentes (Artículo 6), este compromiso adquirido a partir de julio del año 2013 ha sido cumplido por el Comité Ejecutivo a través de la Resolución 02-2014, denominada procedimiento para la formulación y presentación de mandatos para la Reunión de Presidentes, instrumento jurídico que actualiza y deroga el procedimiento para la adopción de mandatos por la Reunión de Presidentes del año $201 \mathrm{l}$.

- Establecimiento de dos tipos de actos normativos para el Comité Ejecutivo. Resoluciones y Recomendaciones

Mientras el derogado Reglamento de actos normativos refería al Comité Ejecutivo únicamente para la aprobación de reglamentos e instrumentos elaborados por los órganos y secretarías del sistema, el Reglamento para la adopción de decisiones establece que el Comité Ejecutivo podrá emitir resoluciones y recomendaciones.

\subsection{Actos normativos producidos por el Comité Ejecutivo}

El Comité Ejecutivo ha promulgado desde su funcionamiento múltiples resoluciones y reglamentos para el funcionamiento del Comité Ejecutivo, cuyo análisis escapa las dimensiones de este artículo científico no obstante, podemos destacar su trabajo en la búsqueda de ordenar el funcionamiento del Sistema de Integración Centroamericana.

Los temas sobre los que han versado sus actos normativos son variados, y si bien no es posible medir el alcance de sus actuaciones en atención a su producción normativa, si es posible sostener que los temas de sus actos normativos son aquellos sobre los cuales ha habido consenso dentro del órgano. Entre los temas tratados podemos encontrar el más reciente en su resolución $0 \mathrm{I}$ - 2015 que es un llamado a la institucionalidad del sistema al cumplimiento de los mandatos de la Reunión de Presidentes y la normativa del Sistema.

Sus actos normativos han abordado, entre otros, los siguientes temas: la reglamentación de la Organización y Funcionamiento del Consejo de Ministras de la Mujer de Centroamérica, la reglamentación de su propio funcionamiento, la reglamentación para la admisión y participación de observadores ante el SICA, el reglamento relativo a la elección de los titulares de la institucionalidad del SICA, el reglamento para la adopción de decisiones del SICA, el reglamento de la Gaceta Diario Oficial.

Sus resoluciones han estado dirigidas a otros órganos e instituciones del sistema como la Secretaría General del SICA, la Secretaría de la integración social centroamericana, Secretaría de la Coordinación Educativa y Cultural centroamericana, la Secretaría de la Comisión Centroamericana de Ambiente y Desarrollo, la Secretaria del Consejo Agropecuario Centroamericano, la Secretaría de Integración Turística Centroamericana, la Secretaría Ejecutiva del Consejo de Ministros de Salud, Secretaría del Consejo de Ministros de Finanzas, entre otros.

Las referidas resoluciones tienen su fundamento en la atribución del Comité Ejecutivo de velar porque se cumplan las disposiciones del Protocolo de Tegucigalpa, sus instrumentos complementarios y derivados, así como la potestad de aprobar los reglamentos e instrumentos elaborados por las distintas secretarías y órganos del sistema.

En la entrevista realizada a funcionarios y académicos relacionados con el funcionamiento del Comité Ejecutivo se consultó su apreciación sobre la producción normativa del órgano, en este aspecto, los entrevistados han considerado que es un tema que ha mejorado con los años y han destacado su importancia para el fortalecimiento 
de la integración centroamericana, aunque han señalado importantes apreciaciones en este sentido como imprecisiones e insuficiencias en su contenido (Caldentey del Pozo), un lento proceso de negociación y una importante lista de documentos en espera de dar respuesta lo cual ha sido imposible dada la sistematicidad de reuniones del órgano (César Salazar).

Los avances normativos logrados hasta ahora por el Comité Ejecutivo nos permiten sostener que su existencia es plenamente justificable para ordenar el sistema de integración centroamericana y brindar certeza jurídica en sus relaciones. Si bien, su papel pudiese ser aún más beligerante, lo cierto es que sus avances han sido al menos tangibles con el transcurso del tiempo y como plantea Caldentey del Pozo al responder nuestra entrevista, la producción normativa del órgano entorno a la reforma institucional es una de sus fortalezas.

Definitivamente aún quedan importantes instrumentos por aprobar, como un instrumento único que regule procedimentalmente el funcionamiento de las secretarías, un instrumento que establezca el procedimiento a seguir para el cumplimiento de mandatos, la rendición de cuentas de las actividades realizadas por un órgano en relación a los mandatos presidenciales, los plazos para coordinar acciones dentro de la institucionalidad, entre otros.

\section{El funcionamiento del Comité Ejecutivo del SICA}

Habiendo ya abordado la producción normativa del Sistema de integración Centroamericana, con especial referencia al Comité Ejecutivo, mostrando así la trascendencia e importancia del mismo como uno de los únicos tres órganos del sistema a los que el Protocolo de Tegucigalpa les reconoce la capacidad de tomar decisiones vinculantes en el sistema, corresponde ahora abordar la regulación jurídica de su funcionamiento.

\section{I Regulación normativa}

El Protocolo de Tegucigalpa establece que el Comité Ejecutivo del SICA está integrado por un representante de cada Estado Miembro del SICA, nombrado por el Presidente de la República por intermedio del Ministro de Relaciones Exteriores respectivo (Artículo 24).

Para Miranda (2010) la configuración del Comité Ejecutivo del SICA no está pensada solo para velar por los intereses nacionales, sino para velar por los intereses de la región, opinión que compartimos. Así, la conformación normativa planteada por el Protocolo de Tegucigalpa de un representante de cada Estado implica un carácter de imparcialidad e independencia, así como la actuación de este órgano en nombre de la comunidad (Salazar Grande y Ulate Chacón,2013). Para los autores citados "Este órgano debe funcionar de forma permanente y debe ser totalmente independiente de los Estados" (p. 84). Por su parte, White Gómez (2008) asevera el papel de Comité Ejecutivo como un órgano político de control, formulación programática y coordinación entre regímenes.

Lo anterior denota el grado de representación política que se requería en el órgano, un representante de cada Estado nombrado por el Presidente de su país es una muestra del respaldo político que debe tener el representante por parte de su gobierno. Es importante detenernos a señalar que el Protocolo de Tegucigalpa se refiere al miembro del Comité Ejecutivo del SICA como un representante, de la interpretación de este apartado no se desprende si el representante puede ser funcionario del Estado o no de forma simultánea.

Lo expresado es lo establecido en el Protocolo de Tegucigalpa en cuanto a la conformación del Comité Ejecutivo, no obstante, desde que el Comité Ejecutivo se reunió por primera vez, cada uno de los representantes de los Estados ha sido funcionario de su gobierno de forma simultánea. Embajadores, altos funcionarios del Ministerio de Relaciones Exteriores, y por regla general, los Viceministros de Relaciones Exteriores.

Esta simultaneidad entre ambos cargos definitivamente incide directamente en las actuaciones o resultados del Comité Ejecutivo del SICA, porque el avance en las decisiones sucede más lento que el avance que se tendría con una persona dedicada de forma permanente a las funciones del Comité Ejecutivo del SICA. A pesar de ello, que el representante ante el Comité Ejecutivo del SICA sea un funcionario de alto nivel en su gobierno ha significado, de 
alguna manera, un beneficio para que las decisiones tomadas en el seno del órgano incidan en el gobierno de las naciones que representan.

Esta confluencia de funciones en una misma persona, es para nosotros un principal punto de análisis en el funcionamiento del Comité Ejecutivo, para su estudio se planteó a los entrevistados la siguiente pregunta ¿A su criterio, esto limita o potencia el alcance de las acciones del Comité Ejecutivo?, lo anterior nos permitía obtener un criterio sobre si esta confluencia brindaba ventajas o bien perjudicaba al Comité Ejecutivo.

La opinión en este sentido era tendencialmente dividida, una parte de los entrevistados (Cecilia Argüello, Pedro Caldentey del Pozo, Juan José Figueroa y Silvia Cáceres de Alemán) coinciden en que la representación en el órgano por un funcionario público es una ventaja para el Comité Ejecutivo, esto porque le permitía al representante ser cercano a los principales tomadores de decisión de su país, interactuar de forma fluida con su gobierno, y dota a las decisiones del Comité de peso político dentro de su país ${ }^{76}$.

Por otro lado, algunos entrevistados (Juan Daniel Alemán, Edilma Alemán, José Juan Romero y César Salazar7) no niegan las ventajas enunciadas previamente pero consideran que, en atención a lo preceptuado en el Protocolo de Tegucigalpa, es necesario que el representante de cada país ante el Comité Ejecutivo del SICA sea una persona autónoma sin ejercer un cargo público dentro de su gobierno. Para estos, la configuración comunitaria del órgano es clara en la necesidad de un representante con independencia que resida de forma permanente en la sede del Comité Ejecutivo, esto favorecería el interés regional sobre el interés nacional, personas que tengan acceso a los más altos funcionarios de gobierno de su país, que conozcan la integración centroamericana y que actúen en el marco de lo preceptuado en el Protocolo de Tegucigalpa.

Ambas posturas tienen un grado de validez importante, hasta ahora los avances logrados por el Comité Ejecutivo del SICA han sido bajo la representación de funcionarios de gobierno, que como ya adelantábamos, en su mayoría es realizada por Viceministros de Relaciones Exteriores. Esto demuestra de alguna manera que los representantes de cada Estado han logrado importantes avances en el ejercicio de este cargo ante el SICA, sin embargo, sus capacidades son limitadas en cuanto a poder reunirse de forma periódica porque tienen que responder a agendas nacionales de gobierno.

Que el representante ante el Comité sea por regla general el Viceministro de Relaciones Exteriores, ha significado desde nuestro punto de vista, que el funcionamiento del Comité sea débil porque responde a las posibilidades prácticas de una persona con responsabilidades diversas que no se dedica de forma exclusiva a la integración centroamericana, inclusive representan a sus países en otros foros internacionales, probablemente en circunstancias diferentes los resultados del trabajo del Comité Ejecutivo serían más visibles y permanentes.

En igual sentido, la representación ejercida por el Viceministro de Relaciones Exteriores dentro del Comité Ejecutivo permite consecuentemente que las Cancillerías de los gobiernos jueguen un papel importante, tanto así, que algunos de sus funcionarios forman parte de los dos grupos ad hoc que funcionan a la par del Comité Ejecutivo.

Esto lógicamente tiene como consecuencia que las actuaciones en el seno del Comité Ejecutivo y los grupos ad hoc estén impregnadas de intereses nacionales y de política exterior que corresponden a las tareas de los Ministerios de Relaciones Exteriores, en alguna medida esto podría afectar directamente las acciones del Comité Ejecutivo.

\footnotetext{
${ }^{76}$ Los entrevistados que plantean esta postura son Cecilia Argüello, Secretaría técnica del Comité Ejecutivo, Pedro Caldentey del Pozo, académico dedicado a la integración centroamericana y ex asesor del Fondo España SICA, Juan José Figueroa actual embajador de El Salvador en Nicaragua y Silvia Cáceres de Alemán, embajadora de carrera de Guatemala que en algunos momentos ha representado a su país en el ámbito del Comité Ejecutivo.

${ }^{77}$ En este caso los entrevistados corresponden a Juan Daniel Alemán ex Secretario General del SICA, Edilma Alemán, al momento de esta investigación encargada de negocios de la Embajada de Panamá en El Salvador y participante del Comité Ejecutivo, José Juan Romero, Investigador en temas de integración regional y miembro de la Fundación ETEA, y César Salazar, asesor jurídico de la Secretaría General del SICA.
} 
Es importante tener en cuenta que el alto cargo ejercido en el plano nacional por el representante ante el Comité Ejecutivo, conlleva indiscutiblemente, a una rotación sistemática cada vez que hay un cambio de gabinete de gobierno producto de elecciones presidenciales en los países del ámbito centroamericano, no obstante, este es un fenómeno que se presenta en toda la institucionalidad regional, desde la Reunión de Presidentes, los Consejos de Ministros, etc.

Si bien el carácter permanente que el Protocolo de Tegucigalpa otorga al representante del Comité Ejecutivo pareciera evitar esta rotación, lo cierto es que difícilmente, a nuestro criterio, se pudiese contar con un representante (que aunque no sea miembro del gabinete de gobierno) sobreviva a los cambios de gobierno de cada uno de nuestros países, pues la práctica común es que los cargos de índole política son altamente vulnerables a este tipo de cambios nacionales.

La propuesta de un representante independiente de su gobierno pero con cercanía a los principales tomadores de decisión de su país, es bastante válida y sobretodo, encuentra su fundamento en el Protocolo de Tegucigalpa porque esta persona independiente de su gobierno podría establecerse en la sede del Comité Ejecutivo y sesionar de la forma en que el Protocolo de Tegucigalpa ha preceptuado.

Por lo expresado anteriormente, consideramos que el representante ante el Comité Ejecutivo debería de ser una persona distinta del Viceministro de Relaciones Exteriores pero miembro del gabinete de gobierno de su país para lograr que las decisiones tomadas en el seno del Comité Ejecutivo sean implementadas nacionalmente, aun cuando esta cercanía a la cúpula gubernamental devenga en una temporalidad en el ejercicio de la representación.

A pesar de ello, una transformación de este tipo debe ser planteada cuidadosamente para lograr realmente tener un representante de país con peso político dentro de su gobierno e incidencia directa en el mismo, pero con disponibilidad entera y permanente para el Comité Ejecutivo del SICA. Un cambio de este tipo requiere la voluntad de los principales tomadores de decisión del SICA.

No podemos dejar de resaltar que un cambio en este sentido tiene muchos riesgos que deben ser tenidos en cuenta al momento de valorarse, el principal riesgo es que tal cambio sea contraproducente para el Comité Ejecutivo del SICA y tengamos a un representante dedicado exclusivamente al órgano pero que no tenga capacidad de tomar decisiones vinculantes para su país y por tanto, ponga en juego el peso dentro de su gobierno de las resoluciones emanadas del Comité Ejecutivo del SICA.

\subsection{Conformación del órgano}

Por referencia a documentos de vieja data hay algunos vestigios que demuestran el funcionamiento incipiente del Comité Ejecutivo del SICA para los años 1995 y 1996, así CEPAL (1997), al realizar un estudio sobre la institucionalidad regional del sistema de integración centroamericana hace referencia a que el "Comité Ejecutivo se reunió por primera vez el 4 de mayo de 1995, y lo ha hecho solo cinco veces en 1995 y apenas dos en 1996" (p. 36), así mismo, hace referencia a un primer anteproyecto de Reglamento de actos normativos del SICA como una versión revisada en el marco de la IV Reunión del Comité Ejecutivo del 22 de agosto de 1995. También Otilio Miranda $^{78} \mathrm{~S}$. J al consultarle sobre las razones históricas que detuvieron la conformación del Comité Ejecutivo hasta febrero de 2008, asevera que este órgano se reunió por primera vez en 1995.

A pesar de lo anterior, en apariencia ese incipiente accionar del Comité Ejecutivo rápidamente dejó de funcionar y el órgano dejo de existir de forma práctica durante muchos años. Como señala Blanco Fonseca (2010) mientras se integra el Comité Ejecutivo sus atribuciones debían ser asumidas por el Consejo de Ministros de Relaciones Exteriores.

\footnotetext{
${ }^{78}$ Académico de la Universidad Centroamericana "José Simeón Cañas”'“de El Salvador.
} 
Como plantea Pérez (2010):

El Comité Ejecutivo, a pesar de haber sido creado por el Protocolo de Tegucigalpa, fue integrado por mandato de la Reunión de Presidentes en diciembre de 2004, debiendo iniciar sus funciones en enero de 2005; sin embargo, fue hasta el II de diciembre de 2007, con la aprobación de su Reglamento, que finalmente se constituyó (p.III).

Retomando el planteamiento anterior, en entrevista realizada a Cecilia Argüello (2014) hace referencia a la importancia del Acuerdo XXV de la Cumbre ordinaria de Jefes de Estado y de Gobierno del Sistema de la Integración Centroamericana del 15 de diciembre de 2004 para el impulso en la conformación del Comité Ejecutivo del SICA.

Debe hacerse notar que el acuerdo referido contradice el Protocolo de Tegucigalpa en cuanto a la periodicidad de las reuniones del órgano en cuestión, puesto que indica que este órgano debía reunirse una vez al mes. Adicionalmente, el acuerdo establecía que el Comité debía asegurar la coordinación entre los acuerdos nacionales y regionales para que la integración fuese parte de la agenda de gobierno, para ello los miembros del Comité Ejecutivo debían participar en los Gabinetes de Gobierno de sus países. Este acuerdo establecía que el Comité Ejecutivo debía entrar en funcionamiento en enero de 2005 , lo que nunca sucedió.

En la actualidad el Comité Ejecutivo del SICA está integrado por los viceministros de relaciones exteriores de cada país miembro. Está constituido por 8 representantes por igual número de países que conforman el SICA, este órgano debe contar con un Presidente que el Protocolo de Tegucigalpa plantea sea el representante del Estado sede de la última sesión ordinaria de Presidentes (Artículo 24).

\subsection{Periodicidad de sus reuniones establecida por los instrumentos jurídicos}

El Protocolo de Tegucigalpa señala que las reuniones del Comité Ejecutivo se realizarán una vez por semana y extraordinariamente cuando sea convocado por su Presidente, es relevante recalcar que, el Comité Ejecutivo es el único órgano del SICA al que el Protocolo de Tegucigalpa le establece una periodicidad para sus sesiones.

El establecimiento de sesiones semanales para el Comité Ejecutivo del SICA hace inferir que la intención de los presidentes de Centroamérica al formular tal precepto, es que el órgano funcione sistemáticamente y produzca en la medida de sus funciones. De alguna manera la periodicidad definida para este órgano está íntimamente relacionada a las funciones otorgadas al mismo.

Desde marzo del 2008 hasta octubre del 2015, el Comité Ejecutivo del SICA se ha reunido en 43 ocasiones, reuniéndose aproximadamente de 5 a 6 veces por año, a pesar de que esto contradice el Protocolo de Tegucigalpa, lo cierto es que es imposible que los representantes de cada país puedan reunirse cada semana en el marco del Comité Ejecutivo, teniendo en cuenta que, como ya abordamos en el acápite anterior, el representante ante el órgano ostenta un cargo público en su país.

Por tanto, en estos momentos, la norma que establece la periodicidad semanal del Comité Ejecutivo del SICA carece de eficacia porque su aplicación no ha sido posible en los siete años que el órgano lleva en funcionamiento.

El derogado Reglamento del Comité Ejecutivo del SICA del año 2007 promulgado por el Consejo de Ministros de Relaciones Exteriores, establecía que el Comité Ejecutivo debía reunirse de forma presencial al menos una vez al mes. El nuevo reglamento de organización y funcionamiento del Comité Ejecutivo del año 2012 no se pronuncia sobre la periodicidad de sus reuniones, tema abordado por el Protocolo de Tegucigalpa como norma jurídica originaria del derecho comunitario centroamericano.

En todo caso, el Comité Ejecutivo del SICA en su funcionamiento actual no ha cumplido el ordenamiento jurídico comunitario pues no se reúne de forma periódica una vez al mes o una vez por semana, teniendo más peso las decisiones políticas en cuanto a las reuniones de trabajo del órgano. 


\subsection{Atribuciones del Comité Ejecutivo}

Al ser el Comité Ejecutivo un órgano permanente del SICA creado por el Protocolo de Tegucigalpa es este instrumento jurídico el que regula sus atribuciones (Artículo 24). La primer atribución del órgano es la de aseguramiento de la ejecución de las decisiones que adopte la Reunión de Presidentes, este aseguramiento deberá realizarlo a través de la Secretaría General.

Esta primera atribución plantea importantes cuestiones sobre las que vale la pena detenerse. Primero en la relación cercana entre la Secretaría General y el Comité Ejecutivo; es destacable que no se trata de una cercanía en la que jerárquicamente la Secretaría General se encuentra subordinada al Ejecutivo como erróneamente planteaba el derogado Reglamento del Comité Ejecutivo del SICA del año 2007.

Creemos que cuando el Protocolo de Tegucigalpa hace referencia al aseguramiento de la ejecución por intermedio de la Secretaría General, lo que plantea es una corresponsabilidad en el seguimiento, pero en la que por la propia naturaleza de las funciones de la Secretaría es ésta la que puede conocer de forma más fehaciente el cumplimiento por parte de los demás órganos e instituciones del SICA. La palabra aseguramiento implica evidentemente el seguimiento cercano del Comité Ejecutivo del SICA a los demás órganos e instituciones que conforman la integralidad del SICA.

Esta atribución solo es posible a través de una adecuada coordinación interinstitucional con las demás instituciones del Sistema, sobre este punto existen aún debilidades que deben superarse, al entrevistar a Cecilia Argüello, fue posible constatar que ha habido esfuerzos importantes para mejorar la coordinación interinstitucional pero es algo sobre lo que se debe seguir trabajando, actualmente, el Comité Ejecutivo del SICA trabaja en un acercamiento con las distintas secretarías existentes de cara a "la institucionalización adicional de mecanismos de coordinación y comunicación entre instancias regionales claves" (2014).

Sobre este punto, en entrevista realizada al Director de la Fundación ETEA para la integración, Caldentey del Pozo (20I4) expresa con bastante propiedad que el problema radica en una falta de definición de las reglas del juego en cuanto a coordinación entre instituciones, las secretarías no saben con claridad que debe informarse o que decisiones deben elevarse al Comité Ejecutivo del SICA, esta es una opinión que compartimos porque creemos que es un tema que requiere una regulación normativa que con claridad establezca de qué forma se va a producir la coordinación entre las instituciones del SICA y el Comité Ejecutivo.

La segunda atribución otorgada al Comité Ejecutivo es la de velar para que se cumplan las disposiciones del Protocolo de Tegucigalpa, sus instrumentos complementarios y actos derivados. Es notorio que en este punto la función es bastante diferente a la anterior en dos sentidos, primero porque ya no se trata de asegurar sino de velar por el cumplimiento, conceptos que engloban distintos significados; $y$ segundo porque mientras en la primera atribución se trata del cumplimiento de las decisiones de la Reunión de Presidentes, la segunda se refiere al cumplimiento del derecho comunitario.

Es importante traer a colación lo expresado por Salazar Grande y Ulate Chacón (2013) en referencia a esta competencia, para los autores esta facultad:

Le permitiría al Comité Ejecutivo iniciar (de oficio o a petición de un Estado miembro) los procedimientos administrativos correspondientes para constatar el incumplimiento por parte de un Estado Miembro, de las normas comunitarias y en caso de constatar dicho incumplimiento, iniciar directamente causas de responsabilidad ante la Corte Centroamericana de Justicia, previa mediación y búsqueda de soluciones de la controversia planteada (p. 85).

Una tercera competencia otorgada al órgano es la del establecimiento de políticas sectoriales y la presentación al Consejo de Ministros de Relaciones Exteriores de las propuestas necesarias en concordancia con las directrices resultantes de la Reunión de Presidentes. Lo anterior denota la capacidad del Comité Ejecutivo de presentar 
iniciativas al Consejo de Ministros de Relaciones Exteriores, sin embargo, esta capacidad de iniciativa está limitada al ámbito exclusivo de los mandatos o directrices emitidas por la Reunión de Presidentes.

Sobre esta competencia hay que hacer notar fundamentalmente dos cosas, la primera el espíritu de estrecha relación interinstitucional entre el Comité Ejecutivo y el Consejo de Ministros de Relaciones Exteriores, lo que refleja la necesidad de coordinación entre ambos órganos, y en un segundo momento es importante reflejar que aunque una primera lectura de la competencia otorgada hace parecer que la capacidad propositiva del Comité Ejecutivo es absoluta, en realidad está limitada a la coherencia con una directriz emanada de la Reunión de Presidentes.

Otra de las competencias otorgadas al Comité Ejecutivo es la de someter mediante su Presidente al Consejo de Ministros de Relaciones Exteriores el proyecto de presupuesto de la organización central del Sistema de Integración Centroamericana lo que hasta hoy, representa una confusión dentro del sistema, puesto que normativamente no está regulado que debe entenderse por organización central.

La siguiente competencia otorgada al Comité Ejecutivo está referida a su capacidad propositiva, esta vez en relación al establecimiento de secretarías u órganos subsidiarios que el Comité considere necesaria o estime convenientes para el logro de los objetivos del SICA y la participación de todos los sectores vinculados al proceso y al desarrollo de la región. La proposición debe ser realizada al Consejo de Ministros de Relaciones Exteriores.

Esta facultad propositiva demuestra que el poder de decisión sobre estos temas lo tiene el Consejo de Ministros de Relaciones Exteriores y las facultades del Comité Ejecutivo se encuentran limitadas a una actuación propositiva.

Sobre el tema de iniciativa Salazar Grande (2010) plantea que el Comité Ejecutivo en su carácter de órgano permanente "debe ser un órgano colegiado, técnico, que asesore al Consejo de Ministros especialmente nombrado y que se le otorguen competencias de iniciativa normativa" (p. 3/3).

Otra atribución otorgada al Comité Ejecutivo es la de aprobación de los reglamentos e instrumentos que se elaboren por las secretarías u órganos del Sistema de Integración Centroamericana. Sobre esta atribución se centran una importante cantidad de resoluciones del Comité Ejecutivo en sus años de funcionamiento, no solamente aprobando los reglamentos de las Secretarías u Órganos, también instruyendo a las Secretarías a presentar las propuestas o borradores de reglamentos internos. Esta competencia ha sido reconocida también por la Corte Centroamericana de Justicia en su opinión consultiva del 20 de octubre de 2010 (Salazar, 20l4).

Es importante evidenciar que la facultad otorgada al Comité Ejecutivo ha pasado de ser una facultad propositiva a tener competencia de aprobación de instrumentos jurídicos. Se debe resaltar que la referencia a la aprobación de instrumentos elaborados por las Secretarías y órganos del SICA abre la puerta no solamente a la aprobación de reglamentos internos como ha sido la práctica del órgano, sino a otro tipo de instrumentos jurídicos no definidos normativamente.

El Comité Ejecutivo también tiene competencia para revisar los informes semestrales de las actividades realizadas por la Secretaría General y las demás Secretarías, y trasladarlos al Consejo de Ministros de Relaciones Exteriores con las observaciones y recomendaciones que el Consejo de Ministros respectivo hubiese realizado. Lo anterior debe ser realizado por lo menos un mes antes de la próxima Reunión de Presidentes.

Consideramos que la razón fundamental de la atribución anterior es la división de poderes a la manera como ocurre en el plano nacional, de tal forma que un órgano o institución tenga cierto control sobre las actuaciones de otro con el objetivo de garantizar el logro del fin primordial, en este caso el objetivo fundamental de la integración centroamericana.

Desde nuestro punto de vista la naturaleza de esta competencia es la de revisar que las actuaciones de las Secretarías estén acordes a los objetivos estratégicos de la integración centroamericana, y acordes a los objetivos del órgano al que sirven de secretaría. 
Esta competencia coloca al Comité Ejecutivo como un filtro que vele por el cumplimiento del interés comunitario en las actuaciones administrativas de la Secretaría General y las secretarias sectoriales; a pesar de ser a nuestro juicio, una competencia positiva para controlar las actuaciones de las secretarías es una competencia aún no desarrollada con propiedad. A través de la entrevista realizada a Caldentey del Pozo manifiesta que las Secretarías no tienen claridad sobre qué temas deben rendir informe o elevar al Comité Ejecutivo del SICA, normativamente esto no está contemplado en ningún instrumento jurídico.

Otra competencia del Comité Ejecutivo se encuentra regulada en el artículo 3 I del Protocolo de Tegucigalpa y es recibir las iniciativas o propuestas de acuerdos o tratados para elevarlas al Consejo de Ministros de Relaciones Exteriores con sus observaciones y recomendaciones.

Las competencias delegadas al Comité Ejecutivo no han sido numerus clausus puesto que además de las que ya hemos enunciado, el Protocolo de Tegucigalpa deja la puerta abierta para que nuevas competencias puedan ser otorgadas a este órgano en cualquier momento a través del Protocolo de Tegucigalpa y sus instrumentos derivados o complementarios (Artículo 24, inciso h).

En relación a este tema en la entrevista realizada a funcionarios y académicos se consultó sobre su apreciación en cuanto a las atribuciones del Comité Ejecutivo, si consideraban que estas eran suficientes, estaban limitadas, debían aumentarse, que cambios sugerían que podían realizarse en este sentido y sí consideraban que existía duplicidad de funciones entre el Comité y otros órganos del SICA.

En este punto prácticamente todos los entrevistados coinciden en que las atribuciones del órgano son suficientes y no deben aumentarse, son complejas y bastante amplias, no obstante, el tema de las atribuciones presenta importantes dificultades a señalar.

Para Otilio Miranda, la atribución que le permite aprobar los reglamentos e instrumentos formulados por la institucionalidad regional debe ser modificada porque el Comité Ejecutivo debería someterlos al Consejo de Ministros de Relaciones Exteriores para su aprobación. Si bien consideramos que es una propuesta válida, realmente desde la conformación del Protocolo de Tegucigalpa, pensando en el Comité Ejecutivo como un órgano permanente es legítimo que éste tenga competencias de aprobación de instrumentos.

Sobre este tema, para algunos de los entrevistados, el problema en relación a las atribuciones es que la conformación actual del órgano no permite la ejecución eficiente de las mismas. Para que las atribuciones mencionadas sean efectivamente cumplidas se necesita un representante permanente dedicado de forma exclusiva al funcionamiento del Comité Ejecutivo.

En relación a la duplicidad de funciones con otros órganos del SICA, casi la totalidad de entrevistados considera que no existe duplicidad pero si confusión y falta de conocimiento en cuanto a las competencias de uno y otro órgano; así por ejemplo, para Caldentey del Pozo no existe claridad en cuanto a la ruta a seguir entre Consejos de Ministros, el Consejo de Ministros de Relaciones Exteriores y la Reunión de Presidentes, hace falta regulación específica en este sentido.

Finalmente, sobre este punto es importante señalar que de conformidad al Acta de la XXXV reunión del Comité ejecutivo el tema del funcionamiento del órgano es un punto de reflexión importante en el seno de sus discusiones, en su reunión del 25 de junio de 2014 se discutió la necesidad de que el Comité Ejecutivo asuma el resto de atribuciones que el Protocolo de Tegucigalpa le confiere; en la reunión se señala que atribuciones como la de asegurar la ejecución eficiente de los mandatos de la Reunión de Presidentes por intermedio de la Secretaría General, velar por el cumplimiento de las disposiciones del Protocolo de Tegucigalpa, establecer políticas sectoriales y revisar los informes de las secretarías, son funciones aún no ejercidas. 


\subsection{Reglamentación del Comité Ejecutivo del SICA}

Habiendo abordado en apartados anteriores el Protocolo de Tegucigalpa como instrumento jurídico marco de la integración centroamericana y creador del Comité Ejecutivo, dedicaremos los siguientes apartados a abordar instrumentos jurídicos complementarios que regulan las actuaciones del órgano.

Es importante señalar que en materia reglamentaria en este apartado se abordan los reglamentos del Comité Ejecutivo de los años 2007 y 20I2, no obstante, en palabras de Salazar (20I4) existió un primer reglamento del 25 de julio de 1995, al que en el marco de esta investigación no se tuvo acceso.

\subsection{El reglamento del Comité Ejecutivo del SICA Diciembre de 2007}

En diciembre del 2007, El Consejo de Ministros de Relaciones Exteriores, aprueba el Reglamento del Comité Ejecutivo del SICA, posteriormente se realiza una enmienda al mismo en febrero del año 2008.

Este instrumento jurídico carece de vigencia y validez a partir del 19 de Marzo del año 20I2, fecha en la que el propio Comité Ejecutivo ya en funciones, promulga el nuevo reglamento de organización y funcionamiento del Comité Ejecutivo. A pesar de ser un instrumento derogado, su regulación presentaba insumos importantes de destacar para efectos del estudio de este órgano, sobretodo, teniendo en cuenta que el reglamento estuvo vigente en aproximadamente 5 años de funcionamiento del Comité Ejecutivo y que por tanto, muchos de los actos realizados por este órgano fueron durante este período de vigencia.

Este reglamento contemplaba la existencia de un Vicepresidente del Comité Ejecutivo del SICA ampliando así el mandato del Protocolo de Tegucigalpa que solamente hace referencia a la existencia de un Presidente (Artículo 2), el reglamento planteaba que el Vicepresidente del Comité sería el representante del Estado miembro al que correspondiese la siguiente presidencia Pro-Témpore, reflejando el deseo de continuidad y seguimiento a las acciones del órgano.

El reglamento regulaba, que además de las competencias otorgadas por el Protocolo de Tegucigalpa, este tenía otras adicionales: examinar las iniciativas de nuevos tratados para elevarlas al Consejo de Ministros de Relaciones Exteriores y la potestad de crear grupos de trabajo o comisiones, y contratar consultorías (Artículo 6).

Aparece regulada la figura del representante ad hoc con poder de decisión para los casos en los que uno de los miembros del Comité Ejecutivo no pueda asistir a la reunión convocada (Artículo I2). Este reglamento establecía en su artículo 18 que la Secretaría General del SICA se desempeñaría como secretaría del Comité Ejecutivo, contradiciendo el Protocolo de Tegucigalpa pues las facultades otorgadas a la Secretaría General no contemplan la de ser secretaría del Comité Ejecutivo.

Como señalan Salazar Grande y Ulate Chacón (2013) la Secretaría General del SICA realiza funciones como secretaría del Comité Ejecutivo "lo cual no es una competencia establecida para la Secretaría General en el Protocolo de Tegucigalpa” (p.87).

\subsubsection{Reglamento de Organización y Funcionamiento del Comité Ejecutivo Marzo de 2012}

En Marzo del 2012, el Comité Ejecutivo del SICA aprueba su reglamento de organización y funcionamiento, derogando el reglamento aprobado por el Consejo de Ministros de Relaciones Exteriores en el año 2007. Habiendo iniciado el Comité Ejecutivo sus funciones, era lógico pensar que se promulgara años después un nuevo reglamento tomando en cuenta las contradicciones que existían entre el reglamento previo y el Protocolo de Tegucigalpa.

Este reglamento modifica la disposición del reglamento precedente estableciendo que la sede de reuniones del Comité Ejecutivo será la ciudad de San Salvador (Artículo I), es importante señalar que este nuevo reglamento recoge la incompatibilidad, ya regulada en el reglamento derogado, del cargo de representante ante el Comité 
Ejecutivo con otro cargo remunerado en la institucionalidad del SICA, la ejecución de consultorías para el SICA o para agencias de cooperación internacional cuyos efectos estén relacionados con el sistema (artículo 3). Se debe evidenciar que el reglamento establece esta incompatibilidad en relación a funciones dentro del SICA pero no hace ningún pronunciamiento sobre el ejercicio de cargos públicos de forma simultánea.

Es destacable que este nuevo reglamento reconoce la facultad de conocer sobre los recursos financieros gestionados a través de la cooperación internacional como consecuencia de lo preceptuado en el artículo 2 literal g) del Protocolo de Tegucigalpa (Artículo 5).

El reglamento plantea la posibilidad de invitar a las sesiones a consejeros o asesores previamente acreditados ante el Presidente del Comité (Artículo 7), esto legítima la participación de personas diferentes al funcionario permanente del órgano, en las reuniones del Comité Ejecutivo del SICA. La participación de asesores ha sido una práctica común en las reuniones del Comité Ejecutivo.

El citado reglamento establece de forma similar al reglamento precedente, las funciones del Presidente del Comité Ejecutivo del SICA (Artículo 7), no obstante, hay un elemento diferenciador que vale la pena destacar en este momento. En el reglamento derogado se establecía que la convocatoria a sesiones debía hacerse por intermedio de la Secretaría General del SICA, sin embargo, a partir de este reglamento la convocatoria a sesiones las hace de forma directa el Presidente del Comité Ejecutivo.

Desde nuestro punto de vista, lo anterior responde a una transformación de percepción en cuanto al papel de la Secretaría General, que en el reglamento derogado se consideraba también secretaría del Comité Ejecutivo y por ello debía ser el ente encargado de convocar; percepción que parece haber sido superada.

Actualmente, el Reglamento establece que la secretaría del Comité Ejecutivo será asumida por un equipo técnico del órgano, sin detrimento del apoyo que la Secretaría General de forma permanente brinde al órgano y sus grupos de trabajo (Artículo I4).

El reglamento de organización y funcionamiento del Comité Ejecutivo establece que las reuniones se realizarán en las instalaciones de la Secretaría General, salvo la posibilidad de reunirse en otro lugar en razón de la agenda de trabajo (Artículo 9); un cambio importante a resaltar es que este reglamento no se pronuncia al respecto de la periodicidad de las reuniones del Comité Ejecutivo, superando así, la contradicción que señalábamos en el apartado anterior respecto el reglamento derogado y el Protocolo de Tegucigalpa.

El reglamento plantea algunas consideraciones en cuanto a la agenda de cada una de las reuniones del Comité Ejecutivo, estableciendo que además de la aprobación del acta de la reunión anterior, si fuese necesario, deberá evaluarse el estado de los acuerdos anteriormente adoptados, los acuerdos pendientes de cumplimiento y aquellos a los que no se llegó a consenso en la sesión anterior (Artículo 13), sobre este punto es relevante señalar la función de seguimiento que el Comité Ejecutivo debe realizar a los acuerdos realizados en el marco de sus competencias.

La existencia de un reglamento para la organización y funcionamiento del Comité Ejecutivo del SICA es fundamental para la legitimidad de las actuaciones del órgano y para facilitar la aplicación de los preceptos consagrados en el Protocolo de Tegucigalpa.

El reglamento plantea la posibilidad de invitar a presidentes, secretarios o directores de órganos, e instituciones a las sesiones en las que se realice el informe semestral de actividades. El artículo II de este reglamento establece que las reuniones deberán realizarse con todos los miembros o su representante ad hoc, si no existe quorum se deberá programar una nueva fecha.

En cuando a cuestiones financieras, los gastos de sus miembros correrán por cuenta de los países que representan. El Comité Ejecutivo deberá elaborar su presupuesto y ser incluido dentro del presupuesto de la organización central del SICA para que de acuerdo a lo establecido en el Protocolo de Tegucigalpa sea aprobado por el Consejo de Ministros de Relaciones Exteriores. 
Este instrumento es sin duda un enorme avance en el proceso de integración centroamericana, no obstante se considera que el reglamento tiene algunas carencias importantes, al momento del cuestionario realizado al Prof. Caldentey del Pozo en el marco de esta investigación, el profesor ha señalado importantes debilidades del reglamento; considera que no es un instrumento jurídico funcional porque no establece con claridad sobre cuales temas debe pronunciarse, como debe hacerlo y como debe ser recibido por los otros órganos e instituciones del Sistema, evidentemente esto implica la necesidad de una regulación más profunda y detallada.

Otro de los vacíos que presenta este reglamento es que no se pronuncia sobre cómo va a realizarse la coordinación interinstitucional entre este órgano y los demás órganos e instituciones del SICA. Teniendo en cuenta la naturaleza de sus competencias, es urgente un instrumento jurídico que establezca de forma procedimental, como se va a relacionar el Comité Ejecutivo del SICA con los demás órganos e instituciones del SICA.

El reglamento debió hacer un pronunciamiento sobre la sistematicidad de las reuniones del Comité Ejecutivo estableciendo cuestiones procedimentales que permitieran al órgano reunirse de forma semanal como lo establece el Protocolo de Tegucigalpa. Este instrumento tampoco introduce alguna regulación que establezca el procedimiento por el cual la Secretaría General y el Comité Ejecutivo van a asegurar el cumplimiento de la competencia compartida.

Si bien el reglamento establece que el Comité Ejecutivo elaborará su presupuesto no hace mayor referencia a como se realizará dicho presupuesto, tomando que criterios, ni los plazos de su formulación o aprobación interna que permitan luego elevarlo al Consejo de Ministros de Relaciones Exteriores como parte del Presupuesto de la Organización Central.

En cuanto al proyecto de presupuesto de la organización central que este órgano debe elevar al Consejo de Ministros de Relaciones Exteriores, el reglamento no establece el procedimiento mediante el cual el Comité Ejecutivo recibirá las necesidades presupuestarias de cada órgano e institución ni los plazos en que debe recibirse para que pueda cumplirse con la citada atribución. La falta de esta regulación impide un adecuado cumplimiento de las atribuciones conferidas al órgano.

El reglamento no establece los plazos en los que el Comité Ejecutivo estará abierto a la recepción de los informes semestrales de la Secretaría u otros órganos y secretarias, y que información deben contener dichos informes.

Todo lo anterior dificulta la implementación del Reglamento de organización y funcionamiento del Comité Ejecutivo porque no permite que en la práctica sea un instrumento guía de las actuaciones del órgano que le conduzca al cumplimiento de sus atribuciones.

\section{El papel de la Secretaría General del SICA y su vinculación con el Comité Ejecutivo}

Su funcionamiento y atribuciones escapan la naturaleza de la presente investigación, no obstante, debemos indicar que en algunos momentos la Secretaría General ha sido vista como secretaría del Comité Ejecutivo, sobre todo por lo que regulaba el derogado reglamento del Comité Ejecutivo del SICA.

El nuevo reglamento de organización y funcionamiento del Comité Ejecutivo establece que la secretaría del órgano será ejercida por una unidad técnica, unidad técnica existente desde hace un par de años en la sede de la Secretaría General del SICA e integrada de forma única por la abogada Cecilia Argüello, quién ha colaborado estrechamente con esta investigación.

Sobre este punto consideramos que la Unidad Técnica debe ser fortalecida y dotada de mayor equipo asesor que apoye el funcionamiento del Comité Ejecutivo, esto ha sido discutido en el seno de las reuniones del órgano como se constata en el acta de su XXXV reunión en la que se abordó la necesidad de reforzar la oficina de asistencia técnica y convertirla en una secretaría ejecutiva con funcionarios que brinden apoyo. En esta reunión se propuso 
que el mantenimiento y financiamiento e esta secretaría se realice a través de una donación del Banco Centroamericano de Integración Económica.

El Protocolo de Tegucigalpa establece en su artículo 24 inciso a) una atribución que el Comité Ejecutivo debe realizar por intermedio de la Secretaría General; esta función es la de asegurar la ejecución de las decisiones de la Reunión de Presidentes. Para el cumplimiento de este fin la Secretaría General y el Comité Ejecutivo deben trabajar de forma conjunta.

Adicionalmente, el Protocolo de Tegucigalpa establece que la Secretaría General debe rendir informe semestral de sus actuaciones al Comité Ejecutivo para que este lo eleve al Consejo de Ministros de Relaciones Exteriores, estableciéndose de esta manera otra responsabilidad de relación entre ambos órganos permanentes del SICA.

\section{Funcionamiento de Grupos ad hoc}

El Reglamento de organización y funcionamiento del Comité Ejecutivo del SICA establece en su artículo 5 que el Comité Ejecutivo del SICA puede crear las comisiones o grupos de trabajo que estime conveniente para desempeñar eficientemente su trabajo que no está normado en el Protocolo de Tegucigalpa.

En el marco de esa potestad en la actualidad existen dos grupos ad hoc que trabajan de cerca con el Comité Ejecutivo que trabajan a nivel técnico, un Comité de Seguimiento del Comité Ejecutivo y el Equipo Jurídico de las Cancillerías. Las competencias de ambos grupos no se encuentran reguladas normativamente.

En marzo del 201I, se estableció el Comité de Seguimiento con el objetivo de ejecutar los lineamientos del Comité Ejecutivo

Está integrado por los embajadores designados por los países en El Salvador. Sus tareas comprenden redactar documentos, preparar términos de referencia y solicitar a todas las instituciones del Sistema informes sobre sus proyectos, acciones, resultados, manejo presupuestario y programas de cooperación (Estado de la Región, 20II, p. 384).

Como consta en el acta de la reunión XXXXIII del Comité Ejecutivo del SICA algunas de las tareas asignadas al Comité de Seguimiento versan sobre la revisión de los documentos sometidos a consideración del Comité Ejecutivo.

En nuestra opinión y en concordancia con la mayoría de entrevistados en esta investigación la existencia de grupos ad hoc es justificable y necesaria para avanzar en el trabajo técnico del Comité Ejecutivo permitiendo agilizar procesos operativos que escapan las posibilidades materiales del órgano y sus miembros.

De acuerdo a la información obtenida a través de las actas de la XXXIII y XXXV de reunión del Comité Ejecutivo del SICA ambos grupos ad hoc presentan informe de sus actuaciones al Comité Ejecutivo en cada una de sus sesiones.

El funcionamiento y naturaleza de los grupos ad hoc es para nosotros esencial en el desarrollo de esta investigación, es por ello que una de las preguntas realizadas a los entrevistados estaba destinada a conocer su percepción sobre la existencia de estos grupos. La mayoría de entrevistados considera que la existencia de grupos ad hoc es justificable y necesaria para avanzar en el trabajo técnico del Comité Ejecutivo lo que permite agilizar procesos operativos que escapan las posibilidades materiales del órgano y quienes le conforman. A estos grupos se les debe otorgar facultades específicas por un tiempo determinado para evitar aumentar el aparato institucional del SICA.

\section{Conclusiones}

A partir de lo expuesto es posible concluir que el Comité Ejecutivo se ha destacado por ser un órgano evidentemente intergubernamental que responde a las voluntades políticas de los gobiernos de la región y en el 
que los representantes de gobierno velan por la satisfacción del interés nacional del país que representan y no el interés regional de índole comunitario.

A pesar de su corta existencia material ha dado resultados satisfactorios en el proceso de integración centroamericana, las atribuciones conferidas le permiten tener un papel más beligerante para cumplir los propósitos de la integración regional pero es necesario un replanteamiento de su funcionamiento y configuración.

El funcionamiento del Comité Ejecutivo está rodeado de importantes vacíos normativos que fomentan la inseguridad jurídica en sus actuaciones, debe regularse de forma integral su capacidad de decisión, la relación interinstitucional, la forma de tomar las decisiones, la periodicidad de sus reuniones y las características de los representantes que le conforman.

Consideramos que no es jurídicamente correcto que el Comité Ejecutivo regulo los tipos de actos normativos que pueden producir órganos jerárquicamente superiores o pares, es prudente que la regulación de este tema provenga de la máxima autoridad del Sistema de Integración Centroamericana.

Las atribuciones conferidas al Comité Ejecutivo son bastas y suficientes para lograr el desarrollo del interés regional una vez que el órgano actúe bajo un interés comunitario y no responda al interés de cada país en particular. Las atribuciones conferidas hacen al Comité Ejecutivo uno de los principales órganos para impulsar la integración centroamericana.

El Comité Ejecutivo debe plantearse una serie de cambios en su funcionamiento actual para mejorar el impacto de sus actuaciones en el proceso de integración centroamericana y lograr articular las decisiones regionales en el plano nacional. La integración centroamericana necesita de un órgano regional con capacidad de tomar decisiones comunitarias y la representación política de los gobiernos centroamericanos, el órgano llamado a cumplir esta necesidad es el Comité Ejecutivo.

Al analizar los aspectos jurídicos y políticos del órgano es posible concluir que en relación al Comité Ejecutivo han tenido mayor peso en su funcionamiento, las decisiones políticas de índole gubernamental que los planteamientos de las normas jurídicas, si esta práctica es lo que ha movido el proceso de integración centroamericana, quedaría entonces plantearse la armonización de las normas jurídicas a la voluntad política de sus gobernantes para evitar las contradicciones o dobles discursos entre la voluntad política y la norma.

Los grupos ad hoc existentes han propiciado la discusión técnica y coadyuvado al fortalecimiento del Comité Ejecutivo, pero estos no deben ejercer las atribuciones del Comité Ejecutivo de forma delegada.

El Comité Ejecutivo debe crear un procedimiento a través del cual, por intermedio de la Secretaría General, mide el cumplimiento de los mandatos presidenciales en el tiempo y verifique que los órganos llamados a dar cumplimiento de los mismos estén realizando actuaciones acordes a los mandatos conferidos.

\section{Lista de referencias bibliográficas}

Carta de la Organización de Estados Centroamericanos (ODECA) el I4 de octubre de I95 I

Carta de la Organización de Estados Centroamericanos (ODECA) del I2 de diciembre de 1962

Chorro, M. (2010). Desafíos de la Institucionalidad de la Integración Regional: Una visión desde la perspectiva del cambio institucional y la producción de BPR. En Miguel Chorro, Víctor Blanco, Carlos Roberto Pérez, Luis Cáceres, Francisco Mayorga, Alfredo Flores Sarria y Edgar Chamorro Marín. Cinco ensayos sobre la integración de Centroamérica: Los ganadores del concurso promovido por el BCIE con motivo de su 50 aniversario. Tegucigalpa. BCIE 
Estado de la Región (201I). Capítulo 7. Integración regional. Recuperado el 8 de abril de 2014 de http://unpan I.un.org/intradoc/groups/public/documents/icap/unpan047375.pdf

García Palacios, O; Budier, W; Miranda, M; Gazo Peña, M; Blandino López, N. (20l I). Regulación Constitucional de los Estados miembros y proceso de formación de los actos normativos del sistema de integración centroamericana. San Salvador: UCA

Miranda, O. (2010). Derecho Comunitario de América Central. Managua: UCA

Pérez, C. R. (2010). Logros y desafíos pendientes de la integración centroamericana. En Miguel Chorro, Víctor Blanco, Carlos Roberto Pérez, Luis Cáceres, Francisco Mayorga, Alfredo Flores Sarria y Edgar Chamorro Marín. Cinco ensayos sobre la integración de Centroamérica: Los ganadores del concurso promovido por el BCIE con motivo de su 50 aniversario. Tegucigalpa. BCIE

Reglamento de organización y funcionamiento del Comité Ejecutivo del Sistema de Integración Centroamericana del II de Diciembre del 2007

Reglamento de Organización y Funcionamiento del Comité Ejecutivo del SICA del 19 de Marzo del año 2012

Reglamento de actos normativos del Sistema de Integración Centroamericana del uno de diciembre del año 2005.

Reglamento para la adopción de decisiones del Sistema de Integración Centroamericana del 24 de junio del año 2013

Salazar Grande, C. (2010). El poder de decisión en el SICA y la necesidad de una reingeniería de su sistema político. En Pedro Caldentey y José Juan Romero. EI SICA y la UE: la integración regional en una perspectiva comparada. Córdoba: ETEA

Salazar Grande, C y Ulate Chacón, E. (20I3). Manual de Derecho Comunitario Centroamericano. San Salvador: SICA

Salazar Grande, C. (20/4). El Protocolo de Tegucigalpa: tratado marco del sistema de la integración centroamericana. El Salvador: Editorial ORBI. IURE

White Gómez, E. (2008). Avances y desafíos de la institucionalidad regional. Recuperado el 10 de abril de 2014 de http://unpan I.un.org/intradoc/groups/public/documents/icap/unpan04038I.pdf 
